DOI: $10.12731 / 2306-1561-2013-4-32$

\title{
MULTI-CHANNEL CUSTOMER COMMUNICATION SPECIALIZED ITEM PROGRAMMABLE ITEM SPECIALIZED SERVICE CONNECTION
}

\author{
Matyukhina E.N., Chistyakova M.A.
}

\begin{abstract}
Discusses the construction of hardware and software for customer point of contact for special purposes, the operator node interaction dialog box in the mode of sending and receiving messages, direct two-way negotiations. Describes the functionality of the site, its hardware and a list of the main data structures. Provides a formal description model of subscriber terminal in the notations of extended Petri nets. Are fragments of concrete datalogical implementations of individual program of formal language templates subscription protocol document exchange.
\end{abstract}

Keywords: post office, telegraph device, communication facilities, documentary exchange.

\section{УДК 004.7}

\section{МНОГОКАНАЛЬНЫЙ АБОНЕНТСКИЙ ПУНКТ СПЕЦИАЛИЗИРОВАННОЙ СВЯЗИ}

Матюхина Е.Н., Чистякова М.А.

\section{Аннотация}

Рассматриваются вопросы построения аппаратных и программных средств абонентского пункта связи специального назначения, организации диалогового взаимодействия оператора узла связи в режиме передачи и приема сообщений, проведения прямых дуплексных переговоров. Описаны функциональные возможности абонентского пункта связи, состав его аппаратных средств и перечень основных структур данных. Приводится формальное описание модели функиионирования абонентского терминала в нотациях расширенных сетей Петри. Представлены фрагменты конкретных даталогических реализачий отдельных программных шаблонов формального языка абонентского протокола документального обмена.

Ключевые слова: абонентский пункт, телеграфное устройство, коммуникационные комплексы, документальный обмен. 


\section{Введение}

В настоящее время одной из наиболее острых проблем в обеспечении документального обмена (ДО) на специализированных узлах связи (УС) является крайняя изношенность обширного парка электромеханических телеграфных аппаратов, не говоря уж об их морально устаревших характеристиках, возможностях и низкой надежности $[1,2,3]$. Основу этого парка в подавляющем случае составляют устройства типа PТА-7М, сопрягаемые по высоковольтному стыку. Несколько в меньшем количестве используются аппараты П-115 и П-116, сопрягаемые по низковольтному стыку.

Замена телеграфных аппаратов на автоматизированные рабочие места (AРM), построенных на базе ПЭВМ, является насущной потребностью на многих УС. Наличие программируемого интеллекта ПЭВМ делает несопоставимыми возможности компьютерной техники с примитивными по современным меркам характеристиками телеграфного устройства (ТГУ) [4].

Преимущества ПЭВМ особенно наглядно проявляются при организации подготовки многостраничного сообщения, в процессе которого используются средства редактирования набираемого текста. Поскольку текст сообщения по эксплуатационным правилам ведомства фиксируется на перфоленте, то в случае необходимости его тривиального исправления непосредственно на подготовленном ленточном носителе это занятие становилось низкопродуктивном.

В то же время простейший редактор любого компьютера не только элементарно обеспечивает возможность исправления и сохранения текста, но также позволяет дополнительно использовать специально заранее заготовленные различные шаблоны и форматы для стандартизованных сообщений и т.п. сервис. Кроме того, применение современных компактных носителей (например, флеш-память) и ЛВС для переноса или локальной транспортировки сообщений вместо одноразовых многометровых перфолент заметно повышает производительность труда оператора и улучшает комфортность его работы.

Скорость обмена информацией, которую потенциально может обеспечить ПЭВМ по сравнению с электромеханическим телеграфным аппаратом, превышает технические возможности ТГУ не на один порядок, что создает реальные предпосылки для организации документального обмена по высокоскоростным каналам связи с принципиально новыми возможностями.

С применением ПЭВМ дополнительно обеспечивается существенное упрощение интерактивного взаимодействия оператора с АРМ за счет более наглядного и удобного проблемно-ориентированного диалогового языка телеграфиста. Вместо посимвольного ввода команд используются простые формы интерактивного меню. Каждый технологический шаг в процессе обработки сообщения снабжается ненавязчивой подсказкой, вызываемой по желанию оператора в случае обучения или затруднения в работе. Кроме того, в памяти АРМ сохраняется и документируется вся справочная информация о работе для обеспечения последующего контроля соответствующим должностным лицом за деятельностью оператора. 
Важным аспектом является также экономическая составляющая рассматриваемой проблемы. Так стоимость любой электромеханической ТГУ существенно (едва ли не на порядок!) превосходит цену самого совершенного современного персонального компьютера.

\section{Функциональное назначение абонентского пункта связи}

Многоканальный абонентский пункт связи (АПС) предназначен для упрощения работы и повышения производительности труда оператора. Функции АПС включают в себя реализацию таких основных задач как:

- подготовка и редактирование текстовых сообщений;

- обеспечение привязки к средствам коммуникационной системы для обмена сообщениями и проведения прямых телеграфных переговоров с абонентами автоматизированной системы документального обмена (АСДО) в соответствии с правилами формального языка оператора $L_{\text {anmo }}\left(G_{\text {anтo }}\right)$;

- обмен телеграммами (передача/прием) по прямым каналам связи при взаимодействии с несколькими ТГУ или аналогичными АПС на формальном языке оператора $L_{c э c}\left(G_{c э c}\right)$ по правилам, регламентированным руководством существующей эксплуатационной службы;

- сохранение и распечатка полученных сообщений;

- ввод-вывод строго учитываемых электронных копий сообщений на носитель информации;

- автоматическая регистрация телеграфной документации при выполнении всех технологических операциях обмена информацией;

- формирование аппаратных журналов, справок, отчетов и т.п. статистической информации за работы, произведенные на АПС;

- установка различных опций, упрощающих технологический режим обмена (например, фиксация набранного заголовка сообщения при его многократном использовании, включение автоматического формирования ответа за принятое сообщение и т.п.);

- создание и использования шаблонов (бланков) типовых телеграфных сообщений и т.п.

Функциональные возможности и конструктивное исполнение образцов АПС соответствовали заданным требованиям эксплуатации техники специального применения.

В частности, в АПС обеспечивались необходимые средства защиты от несанкционированного доступа, безопасности передачи конфиденциальной информации, защиты от механических повреждений и целенаправленных электромагнитных воздействий. При этом, к сожалению, приходилось считаться со все еще сохраняющеюся в телеграфном обмене потребностью ввода-вывода информации на перфоленточный носитель, что существенно «утяжелило» спроектированное изделие. 


\section{Аппаратные средства абонентского пункта связи}

Техническое оснащение АПС реализовано на базе СУЭВМ «РАМЭК ПК 19-1», в составе которой предусмотрено наличие [5]:

- центрального процессора и оперативной памяти, удовлетворяющие требованиям эксплуатации в специализированных приложениях;

- накопителя на жестких магнитных дисках, на котором хранится программная часть комплекса автоматизации;

- многоканального интеллектуального микропроцессорного контроллера на базе терминального электронного модуля (ТЭМ), обеспечивающего сопряжение АПС с несколькими старт-стопными линиями связи;

- полносимвольной клавиатуры и графического манипулятора типа «мышь»;

- д дополнительной приставки с аналогом клавиатуры телеграфного аппарата;

- перфоленточного устройства ввода-вывода;

- устройств вывода информации (цветной монитор, принтер);

- оборудование ЛВС.

На крупных УС в целях экономии единственные экземпляры перфоустройства и печати, сопряженные с одним из АПС, могут использоваться как коммунальные средства для нескольких АРМ, объединенных, например, ЛВС, или путем ручного переноса информации на портативном носителе (флеш-память).

\section{Диалоговое обеспечение АПС}

Диалоговое обеспечение АПС построено с использованием техники «меню», экранных форм, многоярусных «всплывающих окон» и функциональных клавиш, предоставляющих оператору простой, удобный и легко адаптируемый доступ к техническим средствам для проведения интерактивного взаимодействия в технологическом процессе подготовки и обмена сообщениями.

В зависимости от характера использования АПС (организация взаимодействия с коммуникационной системой или обмена по прямым направлениям связи с аналогичными АПС или ТГУ), в нем, соответственно, предусматривается инсталляция одного из двух вариантов диалогового обеспечения, эмулирующего формальный язык телеграфиста Laпто (Gaпто) или правила языка службы эксплуатации связи Lсэс (Gcэc).

При взаимодействии АПС с коммутатором в процессе диалога предусмотрено выполнение следующих технологических операций клиентского приложения:

- запуск и настройка АПС [9];

- идентификация пользователя для доступа к техническим средствам АПС и логическое соединение с коммуникационной системой путем ввода оператором текущего пароля в ответ на запрос коммутатора $[10,11,12]$;

- выбор режима работы в главном меню (подготовка сообщения, передача, прием, переговоры, получение справок, просмотр текстов и т.п.); 
- ввод - вывод текстов сообщений, в том числе с использованием портативного магнитного носителя и перфолент;

- визуализация и распечатка сообщений;

- составление таблиц соответствия позывных условным адресам абонентов;

- получение статистической справочной информации и отчетов по итогам работы АПС по запросу оператора с учетом заданных критериев отбора;

- тестирование и контроль аппаратных средств [13,14,15];

- завершение работы и выход из системы.

В режиме передачи сообщений оператору предоставляется возможность:

- выбора варианта передачи сообщения (одноадресный, многоадресный, по списку);

- указать атрибуты сообщения (категория срочности, гриф сообщения, адресная информация в условных адресах или позывных и т.п.);

- производить непосредственно набор текста сообщения, используя диалоговый редактор;

- производить выборку по имени файла из базы данных заранее подготовленного текста сообщения;

- осуществлять отправку сообщения в коммутатор в режиме, аналогичном электронной почте, без предварительного установления готовности партнера.

Режим приема сообщений характеризуется перманентным анализом информации, поступающей в АПС из коммутатора. При этом производится автоматическая селекция данных на входные команды, тексты принимаемых сообщений, служебные посылки или квитанции в соответствии с формальным языком $L^{\text {выв }}$ anтo $\subset L_{\text {anmo }}\left(G_{a n m o}\right)$. Наличие или отсутствие входной информации автоматически отображается в всплывающем окне на экране монитора в виде мерцающего оповещения.

В режиме приема оператор может:

- получить сведения о наличии или отсутствии принятых сообщений или результирующих квитанций;

- просмотреть принятое сообщение на экране монитора;

- вывести данные на принтер, перфоленту, сохранить в файле под заданным вручную произвольным или автоматически сформированным именем, составленным из регистрационного номера сообщения и адреса отправителя;

- автоматически или вручную отправить подтверждение за принятое сообщение с текстовой частью или без нее;

- просмотреть получаемые результирующие квитанции за ранее отосланные сообщения.

Режим переговора обеспечивает:

- установку прямого логического соединения с любым абонентом АСДО с указанием атрибутов переговоров; 
- проведение дуплексных прямых переговоров в реальном времени с возможностью интерактивной отправки текста, непосредственно набираемого на клавиатуре, или передачи сообщения из заранее подготовленного файла;

- вывод принимаемого сообщения на экран монитора, перфоленту или сохранения в файле;

- завершение прямых переговоров.

В режиме подготовки обеспечивается вызов текстового редактора с возможностями открытия, закрытия или сохранения файла, внесения требуемого исправления в набираемом тексте и т.п. В зависимости от предварительной настройки, осуществляется ручная или автоматическая идентификация имени файла подготавливаемого сообщения. Предусматривается формирование и использование типовых шаблонов текстов сообщений.

Услуги в справочном режиме состоят в формировании по критериям, задаваемым оператором:

- итогового отчета о работе АПС за текущие сутки или иной календарный период времени;

- аппаратных журналов за переданные, принятые сообщения, переданные и принятые подтверждения, за проведенные переговоры и т.п.

Тип журнала задается в всплывающем окне при подведении курсора к соответствующей «иконке».

В режиме контроля появляется дополнительное окно с меню из следующих команд: запрос готовности, тест, проверка, посредством которых обеспечивается проверка логического соединения с коммутатором и сопрягаемыми абонентами непосредственной привязки к АПС.

Режим просмотра обеспечивает визуализацию ранее принятых сообщений. При установке этого режима всплывает окно каталога, содержащего перечень имен. Выбор требуемого файла приводит к высвечиванию соответствующего текста сообщения.

Режим настройки является средством установки различных опций АПС, структурно-адресных таблиц, таблиц позывных абонентов и т.п.

\section{Модель обработки данных}

Формально программная организация обработки ТЛГ-сообщений в АПС может быть представлена Е-сетью (рисунок 1) $E=(P, T, I, O)$,

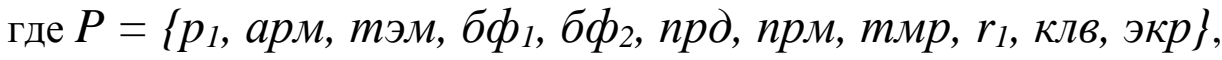

где $p_{1}$ - семафор, интерпретирующий занятость обработчика данных;

арм - макропозиция, характеризующая поступление данных на обработку в ЦП $\mathrm{A \Pi C}$

Мэм - макропозиция, интерпретирующая состояние программных обработчиков интеллектуального контроллера многоканальной телеграфной связи;

$\sigma \not p_{1}, б ф 2$ - позиции, отображающие состояние входного и выходного буферов данных; 
$n p d$, nрм - позиции, отображающие наличие заявок на передачу и прием в программно-аппаратные «окна» межпроцессорной связи;

тмр - макропозиция таймеров;

$r 1$ - решающая позиция выбора направления пересылки результатов программной обработки в выходной буфер для отправки в ТЭМ, на экран дисплея или управление таймерами тмр $\in P$;

клв, экр - периферийные макропозиции ввода команд и данных с клавиатуры (мыши) и вывода на экран дисплея.

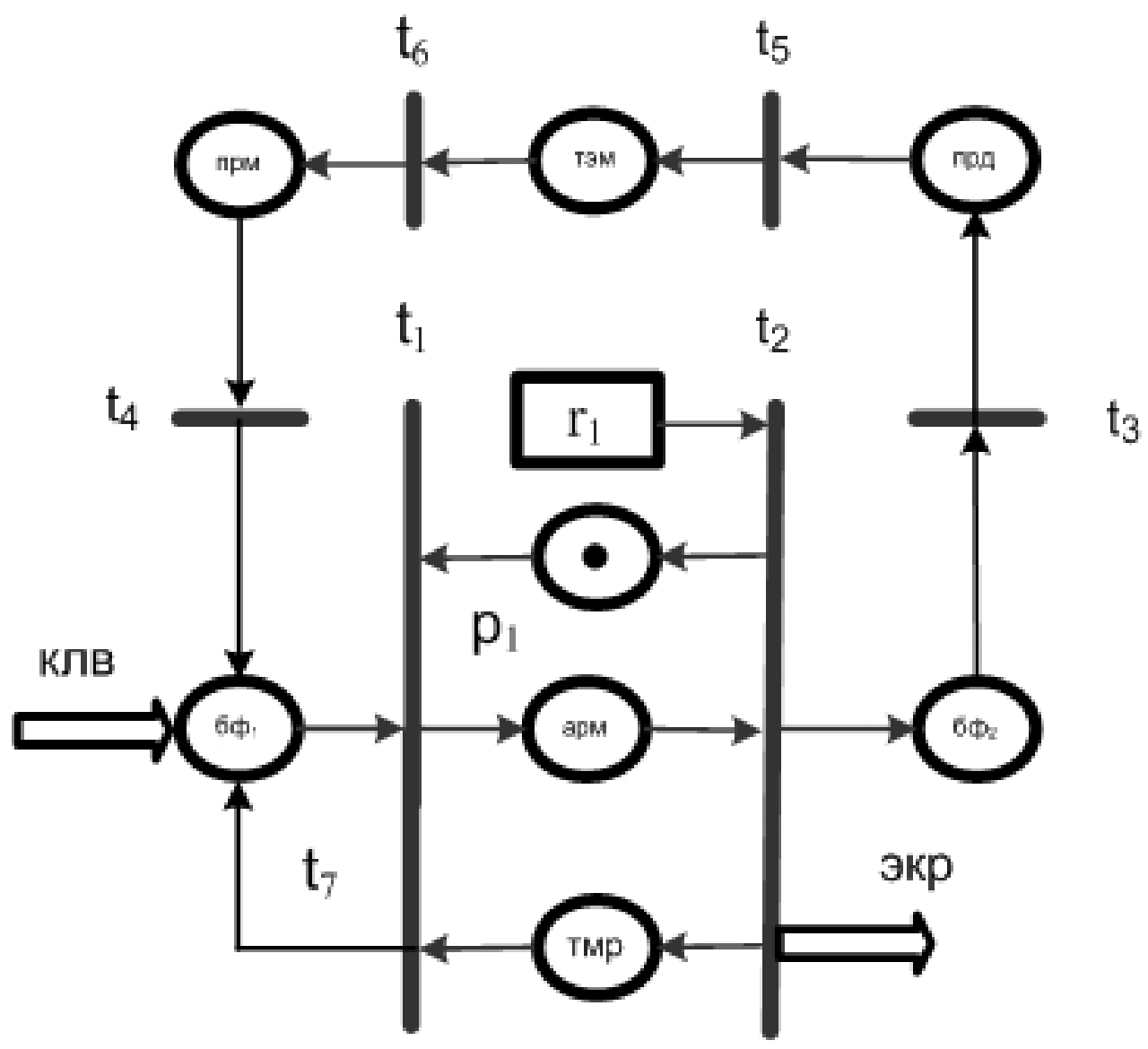

Рисунок 1 - Е-сеть функционирования АПС

$T=\left\{t_{1}, \ldots, t_{7}\right\}-$ множество переходов,

где $t_{1}$ - переход, срабатывающий при поступлении данных на обработку из входного буфера $б \phi_{1}$ в позицию арм $\in P$;

$t_{2}$ - переход управляющего типа, срабатывающий при распределении передаваемых данных на экран;

$t_{3}, t_{4}-$ переходы передачи и приема данных при взаимодействии с межпроцессорным «окном»;

$t_{5}$ - переход, срабатывающий при передаче данных в макропозицию тэм; 
$t_{6}$ - переход, срабатывающий при получении данных из макропозиции $m$ эм на отправку в позицию $п р м \in P$;

$t_{7}$ - переход, преодолеваемый при срабатывании таймеров макропозиции $m p м \in P$ для направления этих сигналов на последующую обработку во входной буфер $б \phi_{1} \in P$.

$$
I=I\left(t_{1}\right) \cup \ldots \cup I\left(t_{7}\right) \text { u } O=O\left(t_{1}\right) \cup \ldots \cup O\left(t_{7}\right) \text { - множество входных и выходных }
$$
позиций, инцидентных переходам $t_{1}, \ldots, t_{7} \in T$.

Процедура смены разметок при срабатывании макроперехода $t_{2} \in T$, управляемого решающей позицией $r_{l}$, описывается следующим соотношением:

$$
\begin{aligned}
& \prod\left(t_{2}\right):\left(\mu\left(r_{1}\right)=\phi r(i, j, k) \mu(\text { apм })=1, \mu\left(p_{1}\right)=0, \mu\left(б \phi_{2}\right), \mu(\text { ммр }), \mu(э к p)\right) \rightarrow \\
& \left(\mu\left(r_{1}\right):=0, \mu(\text { арм }):=0, \mu\left(p_{1}\right):=1, \mu(б ф 2)+=i, \mu(\text { ммр })+=j, \mu(э к p)+=k\right) \text {; }
\end{aligned}
$$

где метки $i, j, k \in\{0,1, \ldots, n\}$ интерпретируют соответственно команды, тексты сообщений, таймеры, и данные, выводимые на экран макропозицией $а р м \in P$.

Динамика обработки информации, поступающей от оператора АПС, прослеживается следующей циклической последовательностью срабатывающих переходов ... $t_{1}, t_{2}, t_{3}, t_{5}, t_{6}, t_{4}, \ldots, t_{2}, t_{7}, t_{1} \ldots$

Разметка входного буфера $\mu\left(\sigma \phi_{1}\right)>0$ интерпретирует наличие данных на обработку, которые могут поступать из трех источников - от приемника «окна», от таймеров, от устройств ввода (клавиатура, мышь). Аналогично, после их обработки, отображаемой срабатыванием перехода $t_{2}$, рассылка меток под управлением решающей позиции $r_{l}$ в общем случае может производиться одновременно по нескольким направлениям - в выходной буфер $б \phi_{2} \in P$ для передатчика «окна», на управление таймерами тмр $\in P$, на вывод на экран дисплея. Причем число передаваемых меток по разным направлениям может варьировать, например, в зависимости от количества управляемых программных таймеров.

Обработка информации, интерпретируемая макропозицией реально параллельными независимыми процессами ввода-вывода на базе автономных микропроцессоров, тогда как процессы, интерпретируемые позициями арм, прд, прм $\in P$ образуют группу квазипараллельных процессов, реализуемых в одном центральном процессоре.

\section{Команды взаимодействия с коммутатором}

В АПС взаимодействие между ЦП и ТЭМ осуществляется через межмашинное «окно» служебными посылками (СП). 
При работе лексического анализатора анл $\in$ Р в АПС производится разбор всех видов квитанций и служебных посылок формального языка $L^{\text {выl }}{ }_{\text {anmo }} \subset L_{\text {anmo }}\left(G_{\text {anmo }}\right)$, поступающих от коммутатора.

В программах АПС тип tkod служебной посылки определен конечным множеством внутренних управляющих команд $\operatorname{Kod}=\left\{\operatorname{kod}_{1}, \ldots, k_{\mathrm{k}}\right\}$, идентифицированных типом перечисления [6, 7, 8]. На этом множестве команд произведено разбиение на подмножество команд, отсылаемых из ЦП в ТЭМ в процессе интерпретации команд диалогового меню и экранных форм, которые заполняются телеграфистом, и на подмножество команд, индуцированных выводом коммутатором различных оповещений согласно лексемам языка телеграфиста Lвывапто, распознаваемых анализатором АПС.

Перечень управляющих команд в АПС представлен для иллюстрации в сокращенном виде в нотациях языка программирования МОДУЛА-2:

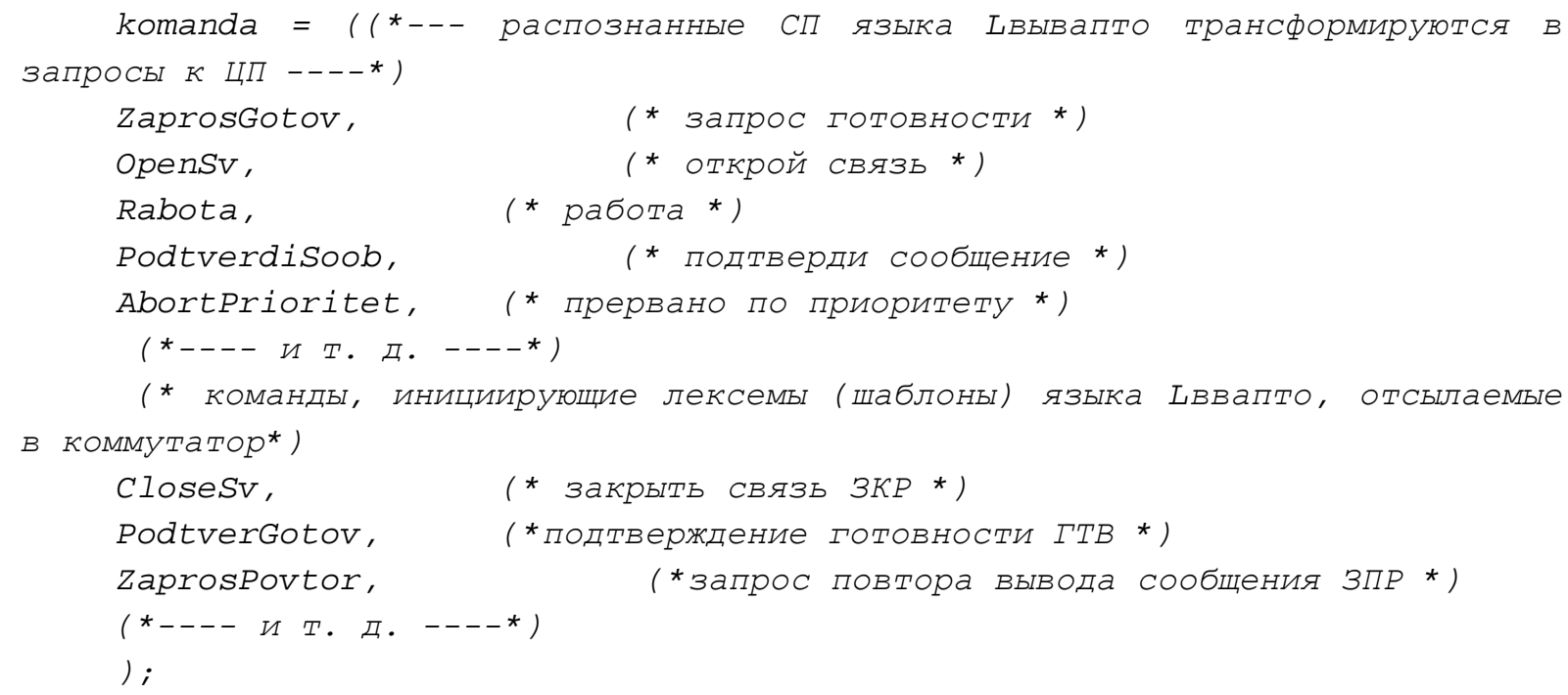

\section{Шаблоны выходных лексем}

Счетное множество выходных лексем $K \varepsilon=\left(\kappa b_{1}, \ldots, \kappa b_{q}, \ldots\right), K \varepsilon \subset D$, передаваемых по старт-стопному каналу из АПС в коммутатор, динамически создается и оформляется при поступлении соответствующих служебных посылок из ЦП в процесс вывода интеллектуального контроллера ТЭМ.

Типы шаблонов лексем формального языка телеграфиста определены конечным множеством $T u=\left\{t u_{1}, \ldots, t u_{h}\right\}, T u \subset T H$. Шаблон $t u \in T u$ состоит из констант знаков телеграфных кодов МТК-2 и необязательных позиций, обозначенных точками ".", которые используются для замены их фактическими параметрами, указанными в служебных посылках.

Упрощенный пример оформления ряда шаблонов Tu, эмулируемых в АПС по

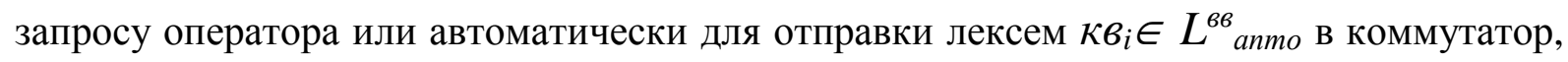
представлен в следующем виде с использованием телеграфного кода МТК-2: 


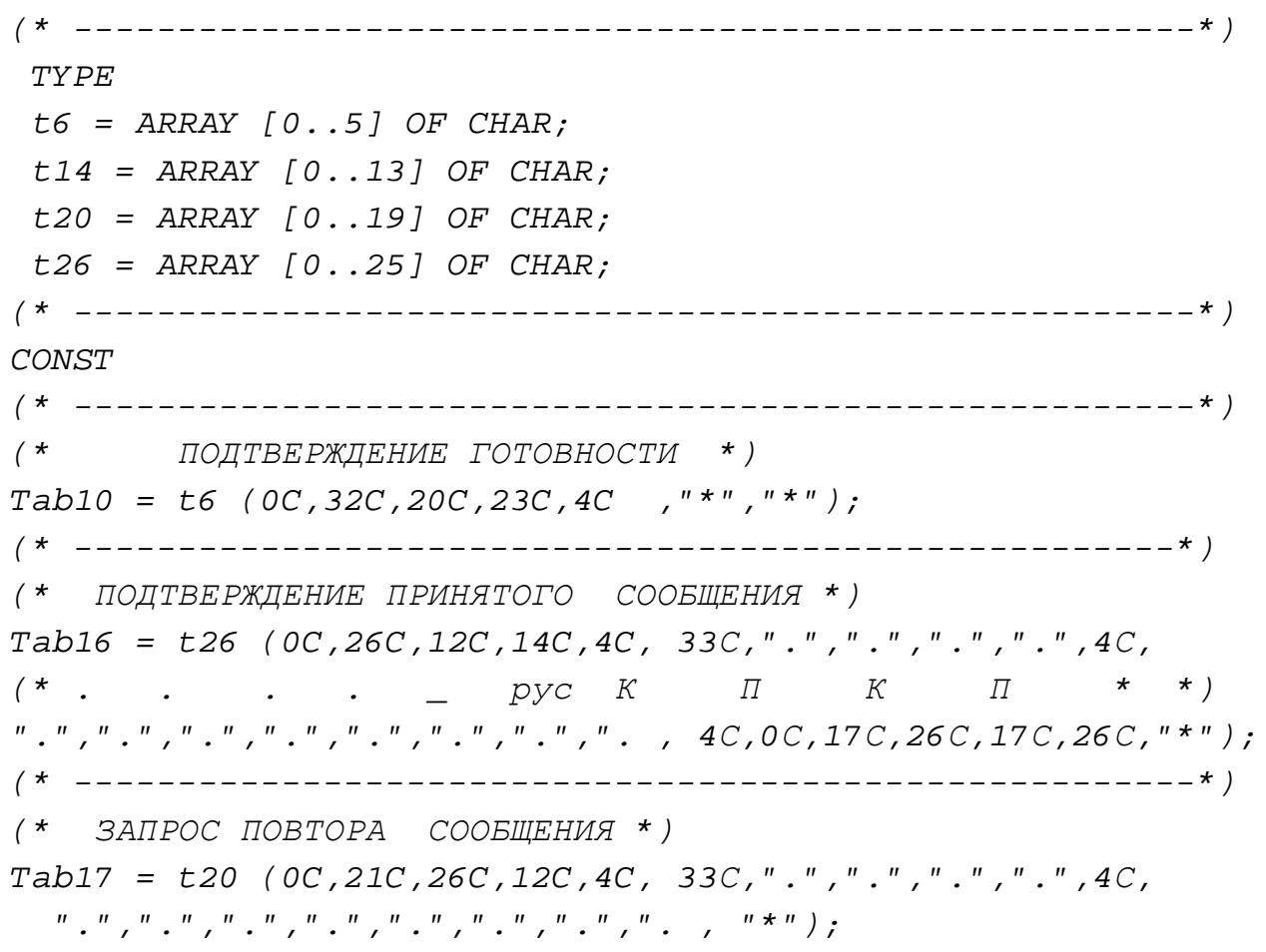

\section{Шаблоны входных лексем}

Шаблоны входных лексем языка $L_{\text {anmo }}\left(G_{a n m o}\right)$, поступающих в АПС из коммутатора, а также лексем языка $L_{c \ni c}\left(G_{c \ni c}\right)$, используются анализатором ТЭМ для распознавания оповещений, квитанций и команд и последующей их трансформации в СП и запросы, направляемые через «окно» на обработку в ЦП в позицию $а р м \in P$ (см. рисунок 1). Перечень шаблонов включает в себя весь репертуар структур правильных цепочек символов, генерируемых коммутатором.

Перечень даталогических форматов шаблонов квитанций и служебных посылок $l e x \in L^{6 b l}{ }_{\text {anто }}$, распознаваемых анализатором АПС, аналогичен сокращенному списку, приведенному выше. Шаблоны, в частности, предназначены для распознания команд и оповещений типа:

- СБРОС ПО ВРЕМЕНИ;

- ОШИБКА КС;

- ОШИБКА В АДРЕСЕ;

- РАБОТА;

- ПОДТВЕРДИ СООБЩЕНИЕ;

- ПРЕРВАНО ПО ПРИОРИТЕТУ;

- СООБЩЕНЕ ПОДТВЕРЖДЕНО;

- ЗАПРОС ГОТОВНОСТИ;

- ОТКРОЙ СВЯЗЬ и т.п. 


\section{Основные структуры данных абонентского пункта связи}

К основным структурам данных, размещаемых в памяти АПС, относятся дескрипторы процессов, дескрипторы телеграфных каналов, формуляры сообщений, динамически создаваемые файлы текстов сообщений и т.п. программные конструкции. Сохраняемые в соответствующих библиотеках переданные, принятые и подготовленные тексты сообщений (и переговоров), результирующие и групповые квитанции, все входящие и исходящие оповещения и служебные посылки, привязанные ко времени, оформляются в форме автоматически поименованных файлов.

В программном обеспечении АПС предусмотрены шаблоны структур аппаратных журналов для переданных и принятых сообщений, прямых переговоров, принятых и переданных квитанций и подтверждений и т.п.

Каждый шаблон журнала представляет собой программный тип записи, который в зависимости от типа журнала определен набором полей, описывающих логическую единицу информации (сообщение, квитанцию).

\section{Заключение}

Поставленные задачи по созданию автоматизированного абонентского комплекса были реализованы и успешно прошли соответствующие испытания и проверки.

Комплексный подход к разработке всех звеньев технологической цепи операций документального обмена и повышения сервиса контроля и управления позволил обеспечить высокий уровень надежности и своевременной доставки сообщений, повысил качество обслуживания должностных лиц УС.

Предоставление пользовательских услуг для абонентов, участвующих в документальном обмене, обеспечивается функционально полным набором возможностей контроля и управления и имеет потенциальные тенденции к дальнейшему развитию. Многоканальные возможности АПС позволили повысить надежность привязи либо одновременно к нескольким коммутаторам автоматизированной системы документального обмена, либо созданию минирегиональной автономной корпоративной подсети [17 - 20].

\section{Список информационных источников}

[1] Матюхина Е.Н., Морозов И.А, Чистякова М.А. Расширение сервисных услуг специализированной связи АСУ ТП // Приборы и системы. Управление, контроль, диагностика. М. 2013. № 4, С. 18-21.

[2] Соловьев Г.А., Соловьев Д.Г. Организация доступа должностных лиц пунктов управления к информационным ресурсам // Труды VIII Российской НТК «Новые информационные технологии в системах связи и управления». - Калуга, 2009. С. $18-21$.

[3] Шабанов А.К. Задачи, проблемы и пути внедрения инновационных технологий в разработках предприятия// Труды IX Российской НТК «Новые информационные технологии в системах связи и управления», Калуга 2010 г. С. 9-15.

[4] Огошкин А.Я., Пиотровский Г.Б., Тимофеев В.М. Создание абонентских пунктов на базе вычислительной техники // Сб. «Повышение эффективности и качества 
передачи дискретной информации», М.: «Электросвязь», 1979 г., выпуск № 5, С $11-14$.

[5] Применение микропроцессорных средств в системах передачи информации/ Советов Б.Я. и др. - М.: Высшая школа, 1987 г. 253 с.

[6] Поликарпова Н.И., Шалыто А.А. Автоматное программирование // Питер, 2010, $176 \mathrm{c}$.

[7] Иванова Г.С. Технология программирования//изд. МГТУ им. Баумана, М. 2006, $335 \mathrm{c}$.

[8] Гагарина Л.Г., Кокарева Е.В., Виснадул Б.Д. Технология разработки программного обеспечения//ИД «ФОРУМ»-ИНФА-М, М.2009, 399 с.

[9] Бурлаченко Т.Б., Морозова Т.Ю. Нейросетевая оптимизация абдуктивных выводов в задачах диагностики технических систем. // Мехатроника, автоматизация, управление. 2008. № 8. С. 19--23.

[10] Сумкин К.С., Морозова Т.Ю., Никонов В.В. Методы управления доступом к информационным ресурсам автоматизированных систем управления на основе канонической модели // Приборы и системы. Управление, контроль, диагностика. 2008. № 10. С. 21.

[11] Сумкин К.С., Морозова Т.Ю. Об использовании нечетких множеств для разграничения прав доступа информационной сети // Наукоемкие технологии. 2008. T. 9. № 7. С. 12.

[12] Морозова Т.Ю., Никонов В.В., Королев А.А. Нейросетевая концепция безопасной передачи данных в беспроводных компьютерных сетях //Сборник научных трудов Sworld. 2008. T. 2. № 1. C. 29-34.

[13] Морозова Т.Ю., Ремонтов А.П., Скворцова Т.И., Чистякова М.А. О возможности компенсации дополнительного шума, вводимого в канал передачи для защиты информации // Инженерная физика. 2009. № 6. С. 22-25.

[14] Морозова Т.Ю., Петров О.М. Вероятностно-статистические методы и средства повышения эффективности защиты и обработки информации в беспроводных сетях. Москва, 2008.

[15] Морозова Т.Ю. Аналитическое выражение и оценка показателя устойчивости защитного шума к компенсации. Часть 2 // Системы управления и информационные технологии. 2008. № 1 (31). С. 16-20.

[16] Морозова Т.Ю., Сумкин К.С. Модели контроля доступа пользователя к ресурсам системы // Сборник научных трудов Sworld. 2007. Т. 2. № 1. C. 11-14.

[17] Матюхина Е.Н., Морозов И.А. Компьютерная сеть специального назначения для систем экологического мониторинга // Промышленные АСУ и контроллеры. 2010. № 1. C. 7-9.

[18] Остроух А.В. Системы искусственного интеллекта в промышленности, робототехнике и транспортном комплексе: монография / А.В. Остроух Красноярск: Научно-инновационный центр, 2013. - 326 с. - ISBN 978-5-90631410-9.

[19] Пермяков А.А. Модуль управления дебиторской задолженностью для телекоммуникационной компании на базе решений SAP FOR TELECOMMUNICATIONS / A.В. Будихин, А.Б. Маврин, А.В. Остроух, А.А. Пермяков // Приборы и системы. Управление, контроль, диагностика. - М.: «Научтехлитиздат», 2007. - №10. - С. 12-16.

[20] Пермяков А.А. Опыт внедрения решений SAP FOR TELECOMMUNICATIONS для управления дебиторской задолженностью на ОАО МГТС / А.В. Остроух, А.А. Пермяков // Вестник Российского нового университета. Серия естествознание, математика, информатика. - М.: РосНОУ, 2007. - Вып. 2. - С. 108-111. 